\title{
A Multi-objective Control Strategy for Three Phase Grid-Connected Inverter during Unbalanced Voltage Sag
}

\author{
Liang JI, Member, IEEE, Jiabin SHI, Qiteng HONG, Member, IEEE, Yang FU, Member, IEEE, \\ Xiao CHANG, Zhe CAO, Yang MI, Member, IEEE, Zhenkun LI, and Campbell Booth
}

\begin{abstract}
This paper presents a new multi-objective control strategy for inverter-interfaced distributed generation (IIDG) to ensure its safe and continuous operation under unbalanced voltage sags. The proposed control strategy can effectively improve the low voltage ride through (LVRT) capability, reduce active power oscillations, and limit overcurrent simultaneously, which are marked as the most important control objectives of IIDG during unbalanced voltage sags. The advanced voltage support scheme, which utilizes positive sequence component, is firstly proposed to maximize the LVRT capability of IIDG during unbalanced voltage sags. Then, to ensure the safety of IIDG, the active power oscillation suppression and current limitation algorithm are designed individually. Based on the control algorithms of such objectives, the multi-objective control method, including scenario classification and reference current determination, is then presented to achieve such three objectives under various system conditions simultaneously. Finally, case studies and evaluations based on MATLAB/Simulink are carried out to illustrate the effectiveness of the proposed method.
\end{abstract}

Index Terms-Active power oscillation suppression, current limitation, inverter interfaced distributed generation, low voltage ride through, multi-objective control, voltage sag, voltage support.

\section{INTRODUCTION}

$I^{2}$ recent years, increasing attention has been paid to the integration of renewable energy into power systems to address the challenges of the global climate change [1-2]. Renewable energy resources, such as solar and wind, are considered as effective solutions for environmental issues and energy crisis. Most of them are connected to the grid via power electronic converters, which have enormously different performances compared with the conventional synchronous generators, especially during system disturbances. Thus, to maintain the safe and continuous operation of IIDGs, the effective control methods of power electronic converters are required.

The control systems of IIDGs are susceptible to voltage sags, which may cause the disconnections of DGs and disrupt the safe and continuous operation [3]. Accordingly, low-voltage ridethrough (LVRT) and voltage support abilities are required for

This work was supported in part by the National Natural Science Foundation of China (61873159), Shanghai Engineering Research Center of Green Energy Grid-Connected Technology (13DZ2251900), Electrical Engineering Shanghai class II Plateau Discipline, and Shanghai Key Laboratory of Power Station Automation Technology.

L. Ji, J. Shi, Y. Fu, Z. Cao, Y. Mi, and Z. Li are with the Department of Electrical Power Engineering, Shanghai University of Electric Power, Shanghai 200090, China (e-mail: jihome2002@sina.cn; 736892015@qq.com;
DGs [4-5]. Besides, during unbalanced faults, DG can perform undesirable output such as high overcurrent which may damage the inverter power electronic switches due to the thermal limit of the device. Moreover, the inverter output active power may appear with large oscillations, which causes the dc-link voltage oscillations and threatens the safety of the dc-link capacitor. Therefore, to ensure the safe and continuous operation of IIDG, an effective control method of the inverter should satisfy the three requirements, in terms of voltage support, active power oscillation suppression and current limitation.

Many researchers have put effort to solve such challenges of DG control during unbalanced voltage sag [6-23]. Many of them are focusing on voltage support and current limitation [618]. In [6-10], the voltage at the point of common coupling (PCC) is well supported by injecting the constant reactive power. However, such methods have difficulty in selecting an appropriate power reference during the specific voltage sag conditions, which may cause an overcurrent risk to the inverter. Therefore, Wang [11] proposed an LVRT strategy that provide $1.5 \%$ of the reactive current per $1 \%$ voltage sag, while Lee [12] injected $2 \%$ of the reactive current with the same voltage sag according to the E. ON grid code [5]. Meanwhile, the phase currents are well controlled within the limits. However, the voltage support capability was not the prior target of such methods. Thus, the voltage level cannot be effectively supported, especially during moderate or low voltage sag conditions. To address such problems, the advanced voltage control techniques upon positive sequence (PS) and negative sequence (NS) were developed in [13-15], which can maximize the voltage support and regulate the phase voltages within the desired range. The main disadvantage of such control method is the high requirement of the inverter capacity. For the low capacity inverter, the controller may not work properly due to the relatively low voltage support capability. By considering the effect of the DG capacity limit, a method for low capacity DG was proposed in [16]. Although the voltage support target is well ensured, the safety of the dc-link capacitor of the inverter

shdlsjb@163.com; shdldxcaozhe@163.com; miyangmi@163.com; lzk021@163.com

Q. Hong, and C. Booth are with the Department of Electronic and Electrical Engineering, University of Strathclyde, Glasgow, G1 1XQ, UK (e-mail: q.hong@strath.ac.uk; campbell.d.booth@strath.ac.uk)

$\mathrm{X}$. Chang is with the State Grid Shanxi Electric Power Research Institute, Shanxi, 030001, China (e-mail: 334690242@qq.com) 
cannot be guaranteed since the active power oscillation is ignored. Besides, a new solution based on the Lagrange multiplier method was also investigated in [17-18] to maximize the positive sequence voltage support. Also, this method is easy-to-implemented for different control objectives, e.g., minimize the negative sequence voltage and the voltage unbalanced factor (VUF). However, the simultaneous realization of multi-objective is not considered in these works, which is essential for the safe operation of the inverter duration the LVRT period.

Some researchers in recent years put effort to suppress active power oscillations [19-23]. These methods effectively damped the active power oscillations by adequately regulating the ratio of active and reactive current references of both positive and negative sequences. In [19-20], in addition to suppressing the active power oscillation, the non-MPPT operation mode was also established for the boost converter. Therefore, both oscillation and increase of the dc-link voltage can be avoided. The main difference between [19] and [20] is the based reference frames. In [21], a control strategy upon $d q$-frame was presented to deal with the power oscillation. However, both active and reactive power references were user-defined, it is difficult to select a suitable value during a given voltage sag condition which cannot guarantee the safety of the inverter in all possible cases. In [22-23], the control methods based on $d q$ frame are presented to improve the output performance of the inverter by coordinating the current amplitude and power oscillation constrains. However, due to the relatively low injected reactive current, the voltage support capability in these methods may not be fully exploited. In this way, the IIDG may face with high risk of disconnection, which influences the safe and stable operation of the power system.

By investigating the existing control methods and practical experiences, it can be concluded that the ideal control of IIDG during the voltage sag should consider the above objectives simultaneously, in terms of voltage support, active power oscillation suppression and current limitation, as to ensure the safe and continues operation of IIDG. In this paper, a new multiobjective control method based on the $d q$-frame for three-phase IIDG is proposed to achieve these control objectives. Firstly, to fully exploit the inverter capability, the active power control method is designed to inject the maximum allowed active power. Secondly, by considering the phase voltage limits, a positive sequence voltage control method is presented to maximize the voltage support capability under various voltage sags. Thirdly, to ensure the safety of the inverter, the control algorithm to limit the active power oscillations and current amplitudes are designed individually. Finally, the multi-objective control strategy involving scenario classification and reference current determination is proposed, which realizes the above control objectives simultaneously by coordinating the current references of each control objective. Compared with the existing methods, the notable advantage of the proposed method is that it can simultaneously realize and coordinate three critical control objectives, i.e., voltage support, current limitation and oscillation suppression, during all voltage sag scenarios. Meanwhile, the proposed method only applies positive sequence voltage

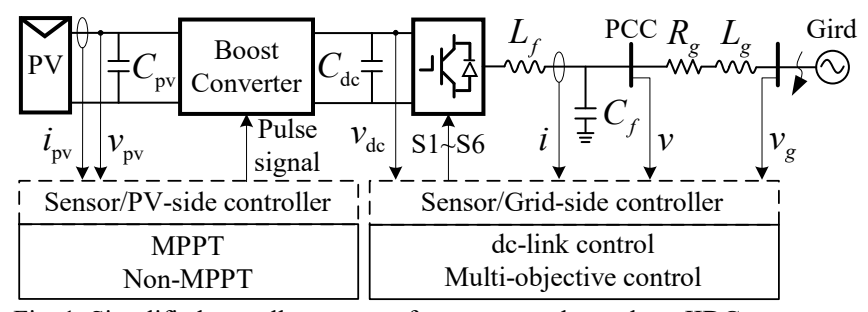

Fig. 1. Simplified overall structure of a two-stage three-phase IIDG system control, which can maximize the voltage support capability while less-affected by the inverter capacity. Moreover, the proposed control strategy can make full use of the inverter capacity. In cases that the inverter has spare capacity after fully realizing such three objectives, the proposed method can use such spare capacity to achieve extra control objectives, such as actively improve system stability and voltage balance.

This paper is organized as follows. Section I gives a brief review of the state-of-the-art control strategies of IIDG. Section II describes the operation of the inverter during unbalanced voltage sag. Section III discusses the active power control and the proposed control objectives with their reference current calculation procedure. Section IV presents a multi-objective control strategy to achieves these objectives simultaneously. In Section V, the effectiveness of the proposed control strategy is evaluated by various case studies. Finally, the conclusions are briefly drawn in Section VI.

\section{INVERTER OUtPUT UNDER UNBALANCED VOLTAGE SAG}

This section describes the typical inverter operation during unbalanced voltage sag conditions, which is vital for the calculation of the reference currents and the realization of control objectives in Section III. Fig. 1 describes the simplified structure and control scheme of a typical IIDG system, which includes two stages: 1) the PV-side boost converter which extracts the PV power and delivers to dc-link, and 2) the gridside inverter which delivers the extracted PV power to the ac grid.

Under unbalanced voltage sag, the voltage vector at PCC is performed in the synchronous reference frame as

$$
v=v^{+}+v^{-}=\left[\begin{array}{c}
V^{+} \cos \left(\omega t+\varphi^{+}\right)+V^{-} \cos \left(-\omega t+\varphi^{-}\right) \\
V^{+} \sin \left(\omega t+\varphi^{+}\right)+V^{-} \sin \left(-\omega t+\varphi^{-}\right)
\end{array}\right]
$$

where $v^{+}$and $v^{-}$denote the positive and negative sequence voltages, $V^{+}$and $V^{-}$denote the amplitudes of $v^{+}$and $v^{-}$, and $\varphi^{+}$and $\varphi^{-}$are their initial phase angle respectively. The output current of the inverter in the SRF can be written as [13]

$$
\begin{aligned}
i=i^{+}+i^{-}= & {\left[\begin{array}{c}
I_{p}^{+} \cos \left(\omega t+\varphi^{+}\right)-I_{q}^{+} \sin \left(\omega t+\varphi^{+}\right) \\
I_{p}^{+} \sin \left(\omega t+\varphi^{+}\right)+I_{q}^{+} \cos \left(\omega t+\varphi^{+}\right)
\end{array}\right] } \\
& +\left[\begin{array}{c}
I_{p}^{-} \cos \left(-\omega t+\varphi^{-}\right)-I_{q}^{-} \sin \left(-\omega t+\varphi^{-}\right) \\
I_{p}^{-} \sin \left(-\omega t+\varphi^{-}\right)+I_{q}^{-} \cos \left(-\omega t+\varphi^{-}\right)
\end{array}\right]
\end{aligned}
$$

where the subscripts " $p$ " and "q" represent the active and reactive current components, and $i^{+}$and $i^{-}$are the positive and negative sequence currents.

Based on the system structure, the relation of the sequence voltages at PCC and grid side bus can be established as 


$$
\begin{aligned}
& v^{+}=v_{g}^{+}+L_{g} \frac{d i^{+}}{d t}+R_{g} i^{+} \\
& v^{-}=v_{g}^{-}+L_{g} \frac{d i^{-}}{d t}+R_{g} i^{-}
\end{aligned}
$$

where $R_{g}$ and $L_{g}$ represent the grid resistance and inductance respectively, $v_{g}^{+}$and $v_{g}^{-}$are the positive and negative sequence voltages at the grid side bus. When designing the proposed control strategy, the grid impedances $\left(R_{g}\right.$ and $\left.L_{g}\right)$ are required to be known [13], which can be obtained by applying the online impedance estimator [24-25]. In order to strengthen the control characteristic of the proposed method, the grid impedance is assumed to be known in this paper.

Considering the positive sequence voltage support objective utilized in this paper, only equation (3) is used. Thus, by inserting (1) and (2) into (3), the relation among $v^{+}$and $v_{g}^{+}$can be described with $V^{+}$and $V_{g}^{+}$, which is written as [18]

$$
V_{g}^{+}=\sqrt{\left(V^{+}-\omega L_{g} I_{q}^{+}-R_{g} I_{p}^{+}\right)^{2}+\left(\omega L_{g} I_{p}^{+}-R_{g} I_{q}^{+}\right)^{2}}
$$

\section{Control Objectives}

In this section, the active power control is firstly described. Then, three control objectives of the proposed methods are introduced individually (Please note that the coordination of the three objectives are introduced in Section IV), which are -Objective 1: Positive sequence voltage support, which aims to maximize the positive sequence voltage within the phase voltage limits.

-Objective 2: Active power oscillation suppression, which aims to limit the active power oscillations within the permissible range.

-Objective 3: Current limitation, which aims to avoid overcurrent risk.

Since the reference current calculation of objectives 2 and 3 depends on different system operation scenarios, the detailed calculation procedures are carried out in Section IV-C (reference current determination). In this section, both objectives 2 and 3 are briefly discussed.

\section{A. Active Power Control}

To fully exploit the DG capacity and mitigate the risk of sudden active power loss during the voltage sags, the proposed control method is designed to inject the maximum allowed active power of the inverter to the grid, which extracted from PV array. To design the active power control, the average active power in the $d q$ domain should be expressed as follow

$$
P=V^{+} I_{p}^{+}+V^{-} I_{p}^{-}
$$

For simplicity, the active power $P$ in this paper is injected via positive sequence active current $I_{p}^{+}$, while $I_{p}^{-}$remains zero. Thus, according to the known value of the generated PV power, the reference current for $I_{p}^{+}$can be obtained as

$$
I_{p_{-} \text {ini }}^{+}=\frac{P_{\mathrm{pv}}}{V^{+}}
$$

where $I_{p_{-} \text {ini }}^{+}$is the initial active current reference that delivers the initial PV power to the gird. The subscribe "ini" denotes that this variable is an initial quantity, which may be modified due to the phase current limitation. $P_{\mathrm{pv}}$ is the initial PV power at maximum power point (MPP).

\section{B. Objective 1: Positive Sequence Voltage Support}

The conventional voltage support methods may not be able to fully support the voltage [6-12] or could be affected by the inverter capacity [13-15]. To address the above limitations, this section develops a method to maximize the positive sequence voltage support. Meanwhile, as to avoid overvoltage during the LVRT period, the following constraint must be fulfilled [7].

$$
V_{\text {max }}=\max \left\{V_{a}, V_{b}, V_{c}\right\} \leq V_{\text {upper }}
$$

where $V_{\max }$ is the maximum voltage amplitude, and $V_{\text {upper }}$ is the phase voltage limit, which is 1.1p.u. [14]. To achieve this, the phase voltage amplitudes are established at first, which are

$$
\left\{\begin{array}{l}
V_{a}=\sqrt{\left[V_{\mathrm{L}} \cos (\gamma)\right]^{2}+\left[V_{\mathrm{S}} \sin (\gamma)\right]^{2}} \\
V_{b}=\sqrt{\left[V_{\mathrm{L}} \cos \left(\gamma+\frac{\pi}{3}\right)\right]^{2}+\left[V_{\mathrm{S}} \sin \left(\gamma+\frac{\pi}{3}\right)\right]^{2}} \\
V_{c}=\sqrt{\left[V_{\mathrm{L}} \cos \left(\gamma-\frac{\pi}{3}\right)\right]^{2}+\left[V_{\mathrm{S}} \sin \left(\gamma-\frac{\pi}{3}\right)\right]^{2}}
\end{array}\right.
$$

where

$$
\begin{gathered}
\left\{\begin{array}{l}
V_{\mathrm{L}}=V^{+}+V^{-} \\
V_{\mathrm{S}}=V^{+}-V^{-}
\end{array}\right. \\
\gamma=\frac{\varphi^{+}+\varphi^{-}}{2}
\end{gathered}
$$

With equations (8)-(11), the maximum phase voltage amplitude $V_{\max }$ can be expressed as follow

$$
V_{\max }^{2}=\left(V^{+}\right)^{2}+\left(V^{-}\right)^{2}+2 V^{+} V^{-} \lambda_{\max }
$$

where

$$
\lambda_{\max }=\max \left\{\cos (2 \gamma), \cos \left(2 \gamma+\frac{2 \pi}{3}\right), \cos \left(2 \gamma-\frac{2 \pi}{3}\right)\right\}
$$

Then, by replacing $V_{\max }$ in (12) with $V_{\text {upper }}$, the maximum positive sequence voltage reference is obtained as

$$
V_{\text {ref }}^{+}=-V^{-} \lambda_{\max }+\sqrt{\left(V^{-} \lambda_{\max }\right)^{2}-\left[\left(V^{-}\right)^{2}-\left(V_{\text {upper }}\right)^{2}\right]}
$$

Finally, by solving (14) and (5), the initial positive sequence reactive current that maximizes the voltage support is deduced

$$
I_{q_{-} \text {ini }}^{+}=\frac{\mathrm{B}-\sqrt{\mathrm{B}^{2}-\mathrm{AC}}}{\mathrm{A}}
$$

where

$$
\left\{\begin{array}{l}
\mathrm{A}=R_{g}^{2}+X_{g}^{2} \\
\mathrm{~B}=X_{g} V_{\text {ref }}^{+} \\
\mathrm{C}=\left(V_{\text {ref }}^{+}-R_{g} I_{p}^{+}\right)^{2}+\left(X_{g} I_{p}^{+}\right)^{2}-\left(V_{g}^{+}\right)^{2}
\end{array}\right.
$$

In addition to maximizing the voltage support capability, $I_{q_{-} \text {ini }}^{+}$is also utilized to classify the scenarios in Section IV-B. Although the injection of $I_{q_{-} \text {ini }}^{+}$can maximize the voltage support, it may fail to achieve objective 2 or 3 in some scenarios 
(e.g., serious voltage sag). Thereby, $I_{q_{-} \text {ini }}^{+}$should be modified to a lower value, which is discussed further in Section IV-C.

\section{Objective 2: Active Power Oscillation Suppression}

During unbalanced voltage sag, the output active power may oscillate with double grid frequency, which leads to the dc-link voltage oscillating with the same frequency. This oscillating voltage can notably affect the long-term life of the dc-link capacitor and even endanger its safety. The suppression of the dc-link voltage oscillations can be achieved by reducing the active power oscillations [19-21]. The relation among the dc voltage and active power oscillations can be expressed as [22]

$$
\tilde{V}_{\text {dc_peak }}=\frac{\tilde{P}_{\text {peak }}}{\omega C_{\mathrm{dc}} V_{\mathrm{dc}}}
$$

where $\tilde{V}_{\mathrm{dc} \_ \text {peak }}$ and $\tilde{P}_{\text {peak }}$ are the amplitudes of the oscillating dc-link voltage and active power respectively, $C_{\mathrm{dc}}$ is the $\mathrm{dc}$ capacitance, and $V_{\mathrm{dc}}$ is the rated dc-link voltage.

To ensure the safety of the capacitor, $\tilde{V}_{\text {dc_peak }}$ must be controlled within the limit $\widetilde{V}_{\mathrm{dc} \_l i m}$. Based on the requirement of a typical commercial film capacitor (e.g., MKP-B32674 [26]), $\tilde{V}_{\mathrm{dc} \_l i m}$ should be within $20 \%$ of $V_{\mathrm{dc}}$. The selection of this ratio mainly relates to the constraint of the dc-link capacitor and the requirement of IIDG users. In this paper, $\tilde{V}_{\mathrm{dc} \_l i m}$ is set as $10 \%$ of $V_{\mathrm{dc}}$, which is a compromise choice. Thus, the limit for $\tilde{P}_{\text {peak }}$ can be calculated upon (17), which is defined as $\widetilde{P}_{\text {lim }}$.

To reduce the active power oscillations within $\tilde{P}_{\text {lim }}$, the instantaneous active power injected to the grid is formulated as a function of the current and voltage vector [20]

$$
p=v \cdot i=(\bar{P}+\tilde{P})
$$

where the average and oscillating terms $\bar{P}$ and $\tilde{P}$ are

$$
\begin{aligned}
& \bar{P}=v^{+} \cdot i^{+}+v^{-} \cdot i^{-} \\
& \tilde{P}=v^{+} \cdot i^{-}+v^{-} \cdot i^{+}
\end{aligned}
$$

By applying equation (1) and (2), and replacing $\tilde{P}$ in (20) with $\tilde{P}_{\text {lim }}$, equation (20) can be rewritten as

$$
\tilde{P}_{\lim }=\sqrt{\left(V^{+} I_{p}^{-}+V^{-} I_{p}^{+}\right)^{2}+\left(V^{-} I_{q}^{+}-V^{+} I_{q}^{-}\right)^{2}}
$$

Equation (21) is to calculate the current references that ensure the active power oscillation suppression objective. The detailed calculate procedure is discussed in Section IV-C.

\section{Objective 3: Current Limitation}

As to avoid the overcurrent risk, the phase current amplitudes $I_{a b c}$ should be described as (22) by developing equation (2)

$$
I_{a b c}=\sqrt{\left(I_{p \mathrm{~L}} \cos \delta+I_{q \mathrm{~L}} \sin \delta\right)^{2}+\left(-I_{q \mathrm{~S}} \cos \delta+I_{p \mathrm{~S}} \sin \delta\right)^{2}}
$$

where

$$
\begin{gathered}
\left\{\begin{array}{l}
I_{p \mathrm{~L}}=I_{p}^{+}+I_{p}^{-} \\
I_{p \mathrm{~S}}=I_{p}^{+}-I_{p}^{-} \\
I_{q \mathrm{~L}}=I_{q}^{+}+I_{q}^{-} \\
I_{q \mathrm{~S}}=I_{q}^{+}-I_{q}^{-}
\end{array}\right. \\
\delta=\left\{\gamma, \gamma+\frac{\pi}{3}, \gamma-\frac{\pi}{3}\right\}
\end{gathered}
$$

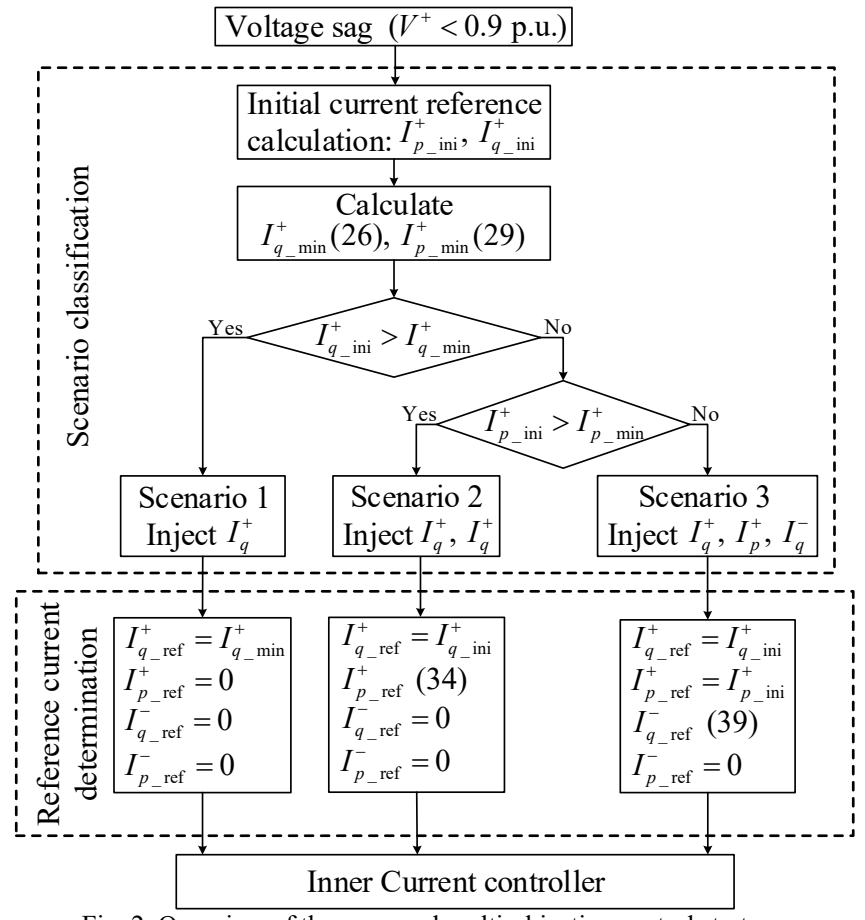

Fig. 2. Overview of the proposed multi-objective control strategy

The current amplitudes $I_{a}, I_{b}$, and $I_{c}$ can be calculated by inserting different $\delta$ in (24) to (22). As to inject the maximum allowed current without overcurrent, equation (25) is defined

$$
\max \left(I_{a}, I_{b}, I_{c}\right)=I_{\text {lim }}
$$

where $I_{\text {lim }}$ denotes the phase current limit of the inverter. $I_{\text {lim }}$ is an adjustable value, which depends on the capacity and thermal limit of the power transistors. The higher maximum allowable current can bring stronger voltage support ability. In this paper, the value for $I_{\mathrm{lim}}$ is setting as 1.2 times of the rated current of the inverter [22]. With equations (22)-(25), the current references can be calculated to avoid the overcurrent risk. The detailed calculation procedure for this objective is discussed in Section IV-C (after the scenario classification).

\section{Multi-objective Control Strategy}

The previous section has discussed the active power control and three control objectives individually. In this section, a new control strategy to achieve multiple objectives is presented. In this way, the inverter can maximize the voltage support capability while ensuring its safety. Moreover, the inverter can actively improve the system stability and voltage balance by full using of the capacity for some operation scenarios.

\section{A. Introduction to the Process of the Control Strategy}

Fig. 2 shows the process of the proposed multi-objective control strategy, which includes four main parts: 1) voltage sag detection, 2) scenario classification, 3) reference current determination, and 4) inner current controller. The details of each step are as follow.

Step 1 Voltage sag detection: The measured phase voltages $V_{a b c}$ at PCC are transformed to positive and negative sequence voltages $\left(V^{+}\right.$and $\left.V^{-}\right)$, utilizing decoupled double synchronous reference frame phase-locked loop (DDSRF-PLL) [27]. If $V^{+}$ 
falls below the preset border value (0.9p.u. upon the Germany LVRT standards [5]), the detection block generates a fault signal to activate the proposed control strategy.

Step 2 Scenario classification: Once the voltage sag has been detected, this block is activated to classify the operation scenario. Firstly, the initial reference currents $I_{p_{-} \text {ini }}^{+}$and $I_{q_{-} \text {ini }}^{+}$ are calculated upon equations (7) and (15). Then, the minimum reactive and active current references $I_{q_{-} \text {min }}^{+}$and $I_{p_{-} \text {min }}^{+}$are calculated by equations (26) and (29), which can evaluate the voltage sag severity and the initial PV power level (discussed in section IV-B). Based on the proposed scenario classification principle (judgement box in Fig. 2), three system operation scenarios can be classified. Each classified scenario matches with a specific current injection mode, which can fully exploit the inverter capacity and ensure its safety.

Step 3 Reference current determination: Depending on the current injection mode of each scenario, four reference current components are determined by the coordination of the three objectives (discussed in section IV-C). Therefore, three control objectives can be achieved at the same time, and the inverter capacity can be fully exploited.

Step 4 Inner current controller: This block is utilized to generate the voltage signals for PWM modulation by controlling the determined reference currents $\left(I_{q_{-} \text {ref }}^{+}, I_{p_{-} \text {ref }}^{+}\right.$, $I_{q_{-} \text {ref }}^{-}$, and $\left.I_{p_{-} \text {ref }}^{-}\right)$. Then, PWM drives the switches of the inverter and inherently realizing the control objectives. Some details of the inner current controller are as shown in Fig. 3 of section IV-D, where four proportional and integral (PI) controllers are contained in the inner controller to regulate four current components.

\section{B. Scenario Classification}

Once the voltage sag is detected, the initial current references $I_{p_{-} \text {ini }}^{+}(7)$ and $I_{q_{-} \text {ini }}^{+}(15)$ are computed. They are used to evaluate the initial PV power level and the voltage sag severity respectively, thus to classify the operation scenarios.

Considering the inverter safety constraints, the realization of the voltage support must ensure objectives 2 and 3 simultaneously. Therefore, the severity of the sag should be evaluated by comparing $I_{q_{-} \text {ini }}^{+}$with the calculated reference currents upon objectives 2 and 3, which defined as follow

$$
I_{q_{-} \min }^{+}=\min \left(I_{q_{-} 1}^{+}, I_{q_{-} 2}^{+}\right)
$$

where

$$
\begin{aligned}
& I_{q_{-} 1}^{+}=\frac{\tilde{P}_{\lim }}{V^{-}} \\
& I_{q_{-} 2}^{+}=I_{\text {lim }}
\end{aligned}
$$

where $I_{q_{-} 1}^{+}$and $I_{q_{-} 2}^{+}$denote the maximum allowed positive sequence reactive current references that ensure objectives 2 and 3 respectively if only $I_{q}^{+}$is injected. They can be calculated by setting $I_{p}^{+}, I_{p}^{-}$and $I_{q}^{-}$in (21) and (22) as zeros respectively.

It should be mention that the voltage support requirement in this research has a higher priority than the active power delivery. Consequently, the inverter can inject the active power into the grid only in case that the voltage has been well-supported to 1.1pu.. In case that the voltage can be fully supported while ensuring objectives 2 and $3\left(I_{q_{-} \text {ini }}^{+}<I_{q_{-} \min }^{+}\right)$, the level of the initial PV power should be evaluated. This can be done by comparing $I_{p \_ \text {ini }}^{+}$with the maximum allowed active current references, which are defined as follow

$$
I_{p_{-} \min }^{+}=\min \left(I_{p_{-} 1}^{+}, I_{p_{-} 2}^{+}\right)
$$

where

$$
\begin{aligned}
& I_{p_{-} 1}^{+}=\sqrt{\left(\frac{\tilde{P}_{\text {lim }}}{V^{-}}\right)^{2}-\left(I_{q_{-} \text {ini }}^{+}\right)^{2}} \\
& I_{p_{-} 2}^{+}=\sqrt{\left(I_{\text {lim }}\right)^{2}-\left(I_{q_{-} \text {ini }}^{+}\right)^{2}}
\end{aligned}
$$

where $I_{p_{-} 1}^{+}$and $I_{p_{-} 2}^{+}$denote the maximum allowed positive sequence active current references that ensure objectives 2 and 3 respectively when both $I_{q}^{+}$and $I_{p}^{+}$are injected. They can be calculated by inserting $I_{q_{-} \text {ini }}^{+}$to (21) and (22), and setting $I_{p}^{-}$and $I_{q}^{-}$as zeros respectively. By comparing $I_{q_{-} \text {ini }}^{+}$with $I_{q_{-} \text {min }}^{+}$and $I_{p_{-} \text {ini }}^{+}$with $I_{p_{-} \text {min }}^{+}$, three different operation scenarios can be obtained. The detailed discussions are given as follow:

1) Scenario 1 (serious voltage sag): If $I_{q_{-} \text {ini }}^{+}>I_{q_{-} \text {min }}^{+}$, the injection of the initial reference current $I_{q_{-}}^{+}$ini will fail objectives 2 and 3, which endanger the safety of the inverter. Thus, this scenario is defined as serious voltage sag scenario (left side of Fig. 2). As to fully support the voltage, only $I_{q}^{+}$is required to be injected in this scenario.

2) Scenario 2 (moderate voltage sag and high initial PV power): If $I_{q_{-} \text {ini }}^{+}<I_{q_{-} \text {min }}^{+}$, the injection of $I_{q_{-} \text {ini }}^{+}$can maximize the voltage support, and both objectives 2 and 3 are ensured. Therefore, the voltage sag is defined as moderate sag. To fully exploit the inverter capacity, the active power can be injected. However, due to that $I_{p_{\text {_ini }}}^{+}>I_{p_{-} \text {min }}^{+}$, the injection of $I_{p_{\text {_ini }}}^{+}$will result in the overcurrent or high active power oscillations. So, the initial PV power is defined as high level (middle side of Fig. 2). In this scenario, both $I_{p}^{+}$and $I_{q}^{+}$are required to be injected.

3) Scenario 3 (moderate voltage sag and low initial PV power): If $I_{q_{-} \text {ini }}^{+}<I_{q_{-} \text {min }}^{+}$and $I_{p_{\text {_ini }}}^{+}<I_{p_{-} \text {min }}^{+}$, the combined injection of $I_{q_{-}}^{+}{ }_{\text {ini }}$ and $I_{p_{-} \text {ini }}^{+}$can fulfill all control requirements. Therefore, this scenario is defined as moderate voltage sag and low initial PV power (right side of Fig. 2). To fully use the capacity and decrease the negative sequence voltage, $I_{q}^{-}$is injected combined with $I_{p}^{+}$and $I_{q}^{+}$.

\section{Reference Current Determination}

Based on the operation scenario and corresponding current injection mode, the final reference currents of each scenario can be determined. Table I summarizes the performance of the IIDG with the proposed strategy under different scenarios.

1) Scenario 1 (serious voltage sag): In this scenario, only $I_{q}^{+}$ is injected. To fully support the positive sequence voltage and ensure objectives 2 and 3, the final current reference for $I_{q}^{+}$ should be determined as

$$
I_{q_{-} \text {ref }}^{+}=I_{q_{-} \text {min }}^{+}
$$

where $I_{q_{-} \min }^{+}$is obtained by (26), which is lower than $I_{q_{-} \text {ini }}^{+}$. Thus, the voltage support that increases $V_{\max }$ to $1.1 \mathrm{p}$.u. is failed, 


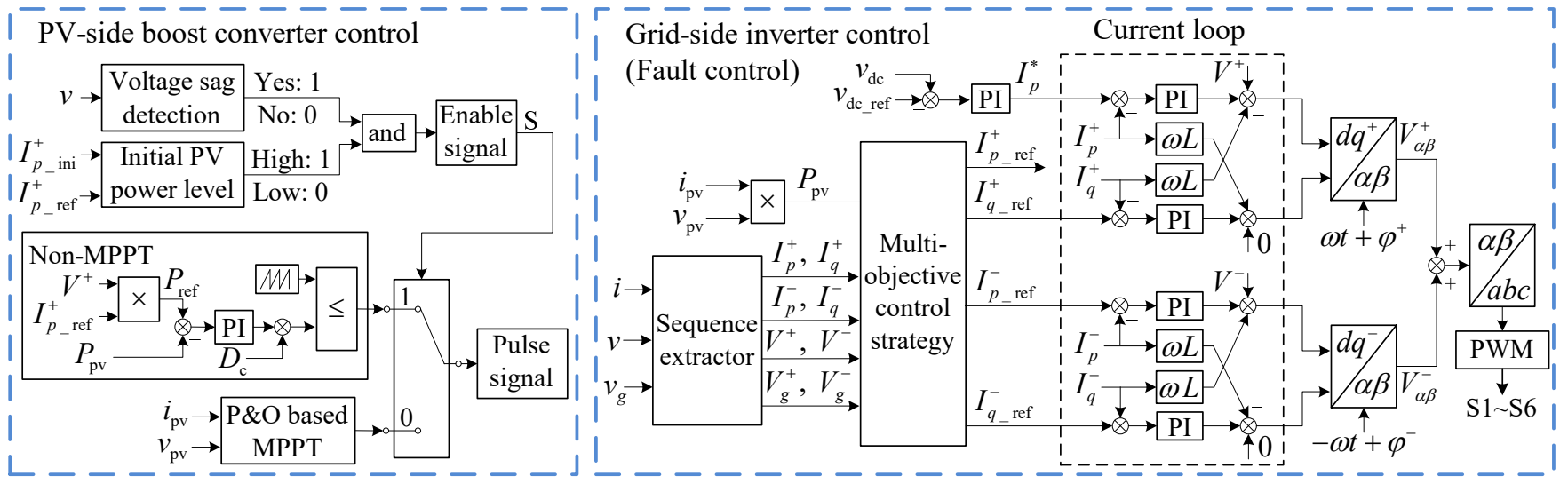

Fig. 3. Control diagram of the two-stage IIDG system

TABLE I

Performance of IIDG With The Proposed Control Strategy

\begin{tabular}{cccc}
\hline Control & \multicolumn{3}{c}{ Performance under Different Scenarios } \\
\cline { 2 - 4 } Requirement & Scenario 1 & Scenario 2 & Scenario 3 \\
\hline $\begin{array}{c}\text { Voltage support } \\
\text { maximization }\end{array}$ & No & Yes & Yes \\
Initial PV & No & No & Yes \\
power delivery & Yes & Yes & Yes \\
Objective 1 & Yes & Yes & Yes \\
Objective 2 & Yes & Yes & Yes \\
Objective 3 &
\end{tabular}

as shown in Table I. Nevertheless, the inverter still maintains relatively high voltage support capability by injecting the maximum allowed value of $I_{q_{-} \text {ref }}^{+}$based on (1).

2) Scenario 2 (moderate voltage sag and high initial PV power): In this scenario, both $I_{P}^{+}$and $I_{q}^{+}$are injected. Since the voltage support can be maximized, the final reference current for $I_{q}^{+}$can be chosen as

$$
I_{q_{-} \text {ref }}^{+}=I_{q_{-} \text {ini }}^{+}
$$

As to avoid the overcurrent and high active power ripple while delivering the active power to the grid, the final active current reference for $I_{p}^{+}$must be chosen as the minimum value among $I_{p_{-} 1}^{+}$and $I_{p_{-} 2}^{+}$described in (29)

$$
I_{p_{-} \text {ref }}^{+}=\min \left(I_{p_{-} 1}^{+}, I_{p_{-} 2}^{+}\right)
$$

3) Scenario 3 (moderate voltage sag and low initial PV power): In this scenario, both $I_{p}^{+}, I_{q}^{+}$, and $I_{q}^{-}$are injected. As the injection of $I_{q_{-} \text {ini }}^{+}$and $I_{p_{-} \text {ini }}^{+}$can fulfill the voltage maximization and initial PV power delivery, the current references for $I_{p}^{+}$and $I_{q}^{+}$are chosen as $I_{q_{-} \text {ini }}^{+}$and $I_{p_{-} \text {ini }}^{+}$respectively. But the reference current for $I_{q}^{-}$must ensure objectives 2 and 3 simultaneously.

Firstly, by replacing $I_{p}^{+}$and $I_{q}^{+}$with $I_{p_{-} \text {ini }}^{+}$and $I_{q_{-} \text {ini }}^{+}$in (21), and setting $I_{p}^{-}$as zero, the current reference that ensures objective 2 is obtained, which defined as $I_{q_{-} 1}^{-}$

$$
I_{q_{-} 1}^{-}=\frac{V^{-}}{V^{+}} I_{q_{-} \text {ini }}^{+}-\sqrt{\left(\frac{\tilde{P}_{\mathrm{lim}}}{V^{+}}\right)^{2}-\left(\frac{V^{-}}{V^{+}} I_{p_{-} \text {ini }}^{+}\right)^{2}}
$$

Then, by using the same way for equation (22), the current reference that achieves objective 3 can be obtained as

$$
I_{q_{-} a b c}^{-}=\mathrm{A}+\sqrt{(\mathrm{A})^{2}-\mathrm{B}}
$$

$$
\left\{\begin{array}{l}
\mathrm{A}=I_{q_{-} \mathrm{ini}}^{+} \cos (2 \delta)-I_{p_{-} \mathrm{ini}}^{+} \sin (2 \delta) \\
\mathrm{B}=\left(I_{p_{-} \text {ini }}^{+}\right)^{2}+\left(I_{q_{-} \text {ini }}^{+}\right)^{2}-\left(I_{\text {lim }}\right)^{2}
\end{array}\right.
$$

and $I_{q_{-} a b c}^{-}=\left\{I_{q_{-} a}^{-}, I_{q_{-} b}^{-}, I_{q_{-} c}^{-}\right\}$represent the calculated negative sequence reactive current reference when the current in phases $\mathrm{a}, \mathrm{b}$ and c reaches to $I_{\max }$ respectively, which can be calculated by inserting different $\delta$ in (24) to equation (36). To ensure the current limitation objective in any condition, the reference current should be defined as

$$
I_{q_{-} 2}^{-}=\min \left(I_{q_{-} a}^{-}, I_{q_{-} b}^{-}, I_{q_{-} c}^{-}\right)
$$

Finally, as to achieve objective 2 and 3 at the same time, the final current reference for $I_{q}^{-}$should be chosen as the minimum value between $I_{q_{-} 1}^{-}$and $I_{q_{-} 2}^{-}$, which is

$$
I_{q_{-} \text {ref }}^{-}=\min \left(I_{q_{-} 1}^{-}, I_{q_{-} 2}^{-}\right)
$$

As concluded in Table I, the voltage support maximization and initial PV power delivery requirements are not always ensured due to the phase current and active power oscillation limits. However, the discussed three control objectives (e.g. voltage support, active power oscillation suppression and current limitation) are ensured simultaneously for all scenarios.

\section{Configuration of the Control Scheme}

The control scheme of the two-stage IIDG system is shown in Fig. 3. During normal operation, the boost converter is operating at MPPT mode. By adopting the de voltage controller which keeps the power balance and dc voltage stabilization, the inverter can operate at constant power (PQ) control mode. During the voltage sag, the proposed multi-objective control strategy is activated to improve the voltage support capability and ensure the safety of the inverter. If the inverter can handle the maximum PV power $\left(I_{p_{-} \text {ref }}^{+} \geq I_{p_{-} \text {ini }}^{+}\right.$, e.g., in scenario 3$)$, the boost converter remains MPPT control mode. Otherwise, if $I_{p_{-} \text {ref }}^{+}<I_{p_{-} \text {ini }}^{+}$(e.g., in scenarios 1 and 2), the inverter is unable to deliver the maximum PV power to the grid due to the safety constraints, the boost converter switches to non-MPPT mode using the control method presented in [19], and reduces the generated PV power to match the maximum allowed active power $\left(P_{\text {ref }}\right)$ of the inverter. In this paper, the design of the nonMPPT control is based on [19].

where 
TABLE II

SYSTEM AND CONTROL PARAMETERS

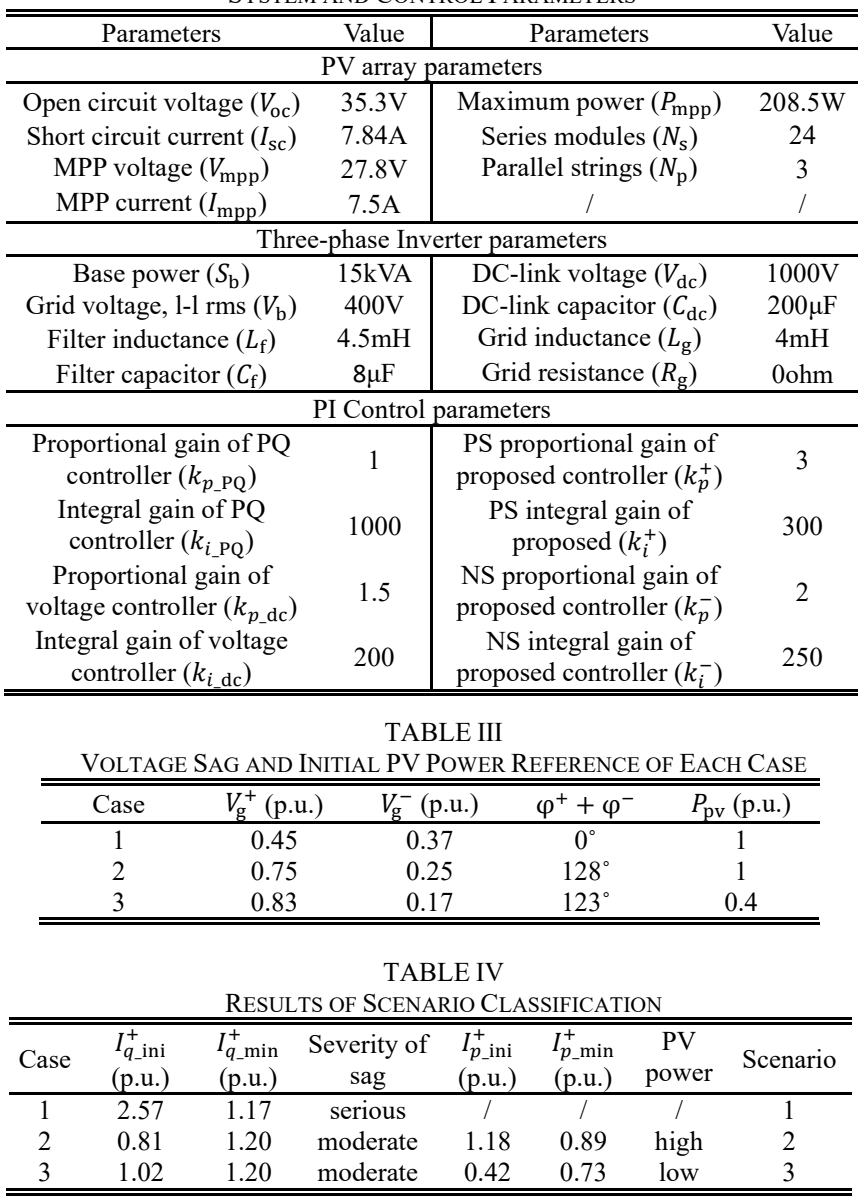

\section{Case Study and Evaluation}

To verify the effectiveness of the proposed multi-objective control strategy, three case studies corresponding to the three scenarios mentioned above are carried out. Firstly, the results of the scenario classification of each case are presented. Then, the performance of the inverter under each scenario is discussed The case studies and simulations are upon MATLAB/Simulink. Fig. 1 shows the tested two-stage system topology, including a $\mathrm{PV}$ array, a boost converter, a $15 \mathrm{kVA}, 400 \mathrm{~V}$ inverter with an LC filter, which connected to the ac voltage source through the conductor. The voltage sags are emulated by the ac voltage source [12-17]. Fig. 3 shows the control scheme of the twostage system, including PV-side boost converter control and grid-side inverter control.

Table II lists the detailed system and control parameters. In all tested cases, the phase current limit $I_{\text {lim }}$ is setting as 1.2 p.u., and the dc voltage oscillation limit $\tilde{V}_{\mathrm{dc} \_ \text {lim }}$ is setting as $10 \%$ of $V_{\mathrm{dc}}$ as stated in Section III-B. Therefore, the active power oscillation limit $\tilde{P}_{\text {lim }}$ is calculated as 0.419 p.u. upon (17).

\section{A. Case Study on Scenario Classification}

To clearly show the operation mechanism of the proposed control strategy, Table III lists the settings of the three cases and Table IV displays the results of scenario classification.

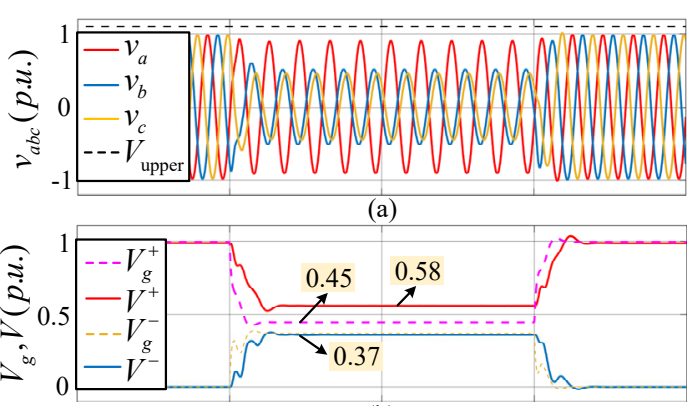

(b)

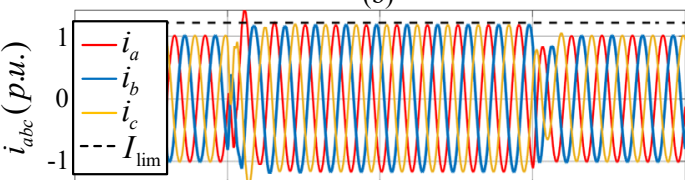

(c)

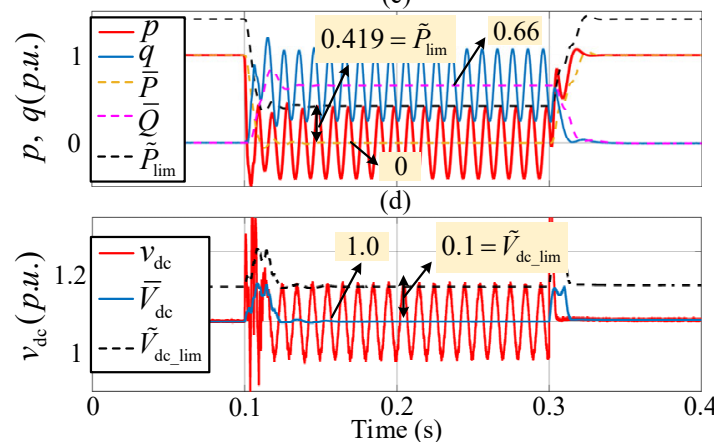

(e)

Fig. 4. Simulation of the proposed strategy for Case 1: (a) phase voltages (b) sequence voltages, (c) phase currents, (d) output power, (e) dc-link voltage.

Case $1\left(V_{g}^{+}=0.45 p . u ., V_{g}^{-}=0.37 p . u.\right)$ : As $I_{q_{-} \text {ini }}^{+}>I_{q_{-} \min }^{+}$, this operation scenario is classified as serious voltage sag.

Case $2\left(V_{g}^{+}=0.75 p . u ., V_{g}^{-}=0.25 p . u.\right)$ : As $I_{q_{-} \text {ini }}^{+}<I_{q_{-} \min }^{+}$ but $I_{p_{-} \text {ini }}^{+}>I_{p_{-} \text {min }}^{+}$, this scenario is classified as moderate voltage sag and high initial PV power.

Case $3\left(V_{\boldsymbol{g}}^{+}=0.83 p . u ., V_{\boldsymbol{g}}^{-}=0.17\right.$ p.u. $)$ : As $I_{q_{-} \text {ini }}^{+}<I_{q_{-} \min }^{+}$ and $I_{p_{-} \text {ini }}^{+}<I_{p_{-} \text {min }}^{+}$this scenario is classified as moderate voltage sag and low initial PV power.

The evaluations of the three cases are discussed in following sections. The classical balanced positive sequence control (BPSC) strategy [29] is presented as a compared method to further illustrate the advancement of the proposed control method. BPSC is an easy-to-implemented and widely-used method due to the current balancing improvement during unbalanced voltage sags. The reactive current injection principle of the BPSC method is upon the E. ON grid code [5], which requires $2 \%$ of the injected reactive current for per $1 \%$ voltage sag.

\section{B. Case 1: Serious voltage sag (Only I Is Injected)}

Fig. 4 shows the performance of the IIDG during serious voltage sag. The proposed control strategy is activated at $\mathrm{t}=0.1 \mathrm{~s}$ and lasts until the sag is cleared at $\mathrm{t}=0.3 \mathrm{~s}$. As shown in Fig. 4(b), the positive sequence voltage $V^{+}$is supported from $0.45 \mathrm{p}$.u. to 0.58 p.u.. However, due to the of the active power oscillation constraint, the voltage support is not maximized $\left(V_{\max }<1.1\right.$ p.u.), which is shown in Fig. 4 (a). However, by injecting the total reactive power to the grid, the voltage support capability is still 


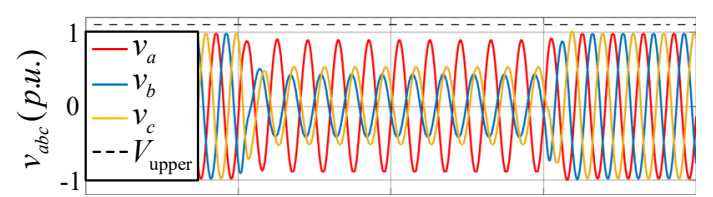

(a)

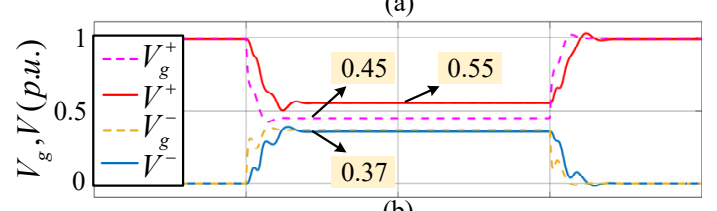

(b)
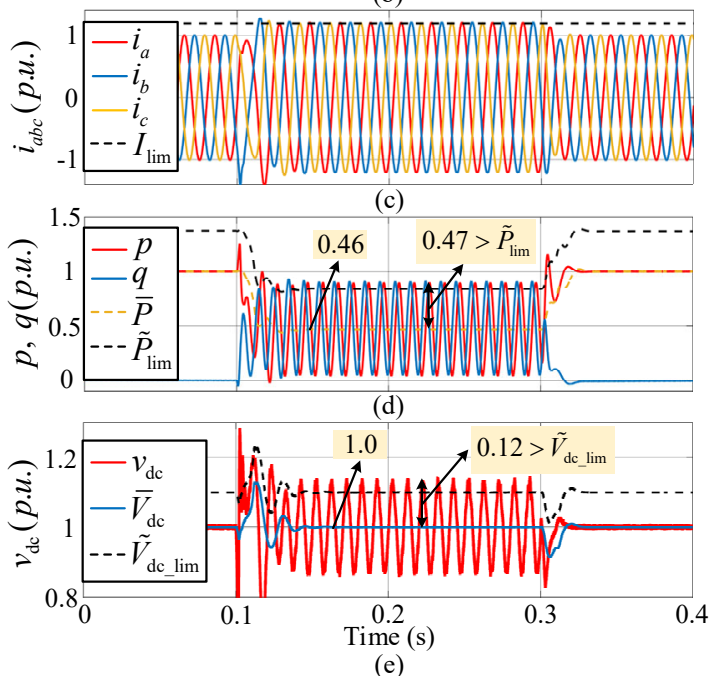

(e)

Fig. 5. Simulation of the BPSC strategy for Case 1: (a) phase voltages, (b) sequence voltages, (c) phase currents, (d) output power, (e) dc-link voltage.

fully enhanced. Fig. 4 (c) and (d) indicate that both phase currents and active power oscillations are well controlled within $I_{\text {lim }}$ and $\widetilde{P}_{\text {lim }}$ respectively. As the maximum allowed active power $\left(P_{\text {ref }}\right)$ of the inverter in this scenario is zero, which is lower than the initial PV power $P_{\mathrm{pv}}$, the boost converter switches from MPPT to Non-MPPT mode. Therefore, by regulating the dc-link voltage, the average active power $\bar{P}$ decreases to zero, and the average dc-link voltage $\bar{V}_{\mathrm{dc}}$ remains 1p.u., which are shown in Fig. 4(d) and (e). Moreover, due to the suppression of the active power oscillation, the dc voltage oscillation is well controlled within $\tilde{V}_{\text {dc } \_l i m}\left(10 \%\right.$ of $\left.V_{\text {dc }}\right)$.

The results of the BPSC method are given in Fig. 5. As seen in Fig. 5 (b), $V^{+}$is supported by 0.1 p.u., which is lower than the proposed strategy (0.13p.u.). As compared Fig. 4(c) with Fig. $5(\mathrm{c})$, both methods can control the phase currents within the limit. However, the BPSC method does not as effective power oscillation suppression performance as the proposed method. Fig. 5(d) and (e) show that both $\widetilde{P}_{\text {peak }}$ and $\tilde{V}_{\text {dc_peak }}$ beyond the allowed limit.

C. Case 2: Moderate Voltage Sag and High Initial PV Power (Both $I_{p}^{+}$and $I_{q}^{+}$are Injected)

Fig. 6 shows the output of IIDG during moderate voltage sag and high initial PV power scenario. As shown in Fig. 6(a) and (b), the voltage support capability is maximized, where $V^{+}$is supported from 0.75 p.u. to 0.85 p.u., and $V_{\max }$ reaches to 1.1 p.u. Fig. 6(c) shows that the phase currents are well limited within $I_{\lim }$. In this scenario, the inverter is still unable to handle the

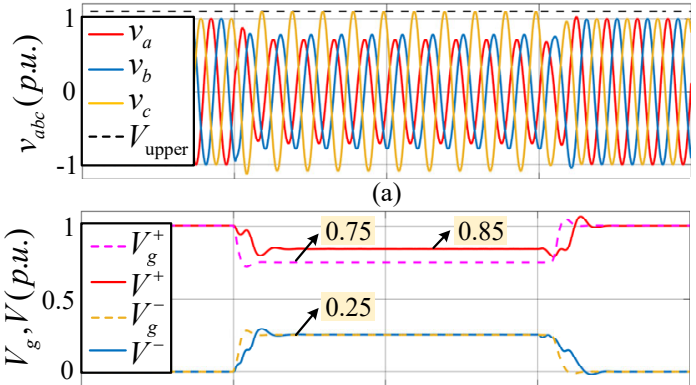

(b)
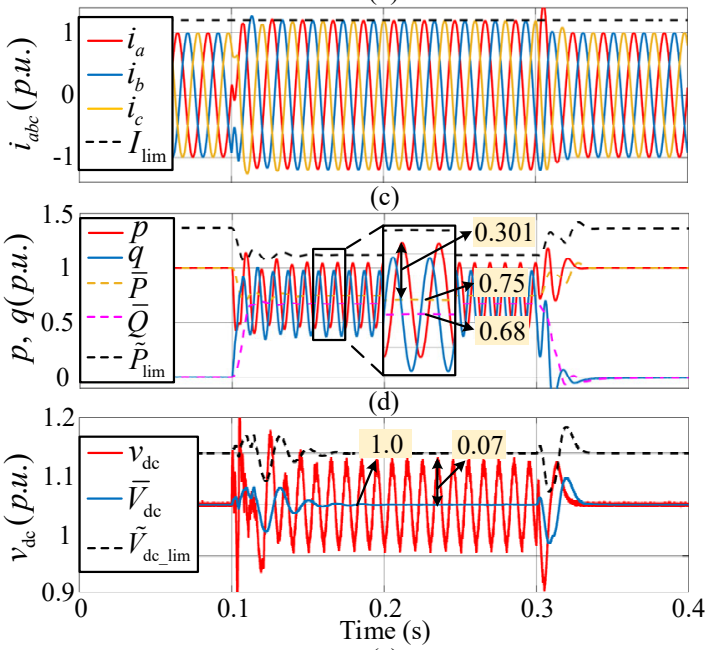

(e)

Fig. 6. Simulation of the proposed strategy for Case 2: (a) phase voltages, (b) sequence voltages, (c) phase currents, (d) output power, (e) dc-link voltage.

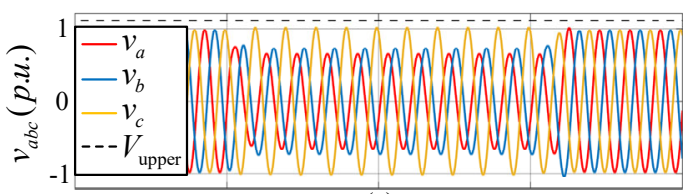

(a)
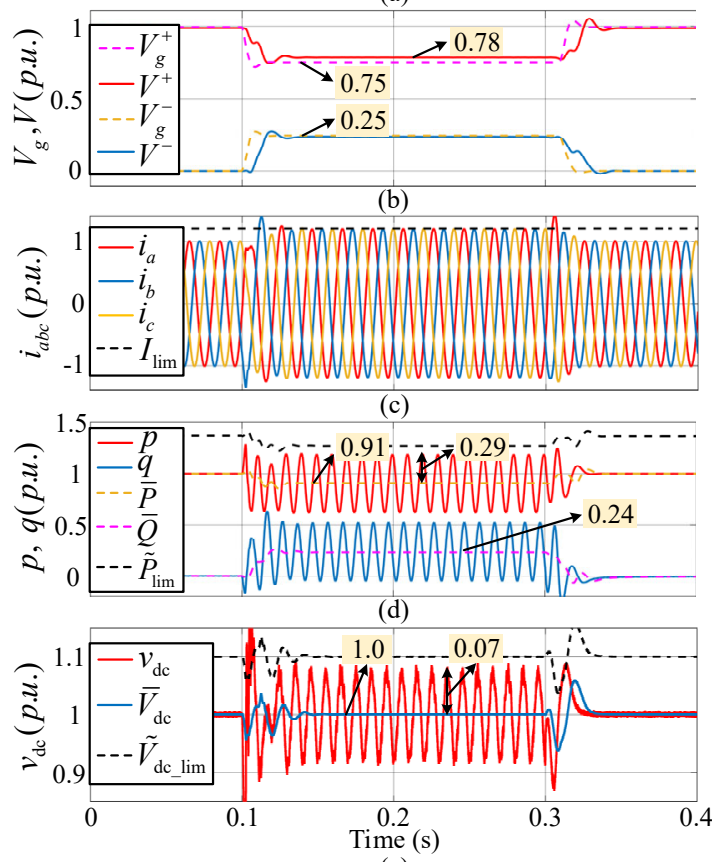

(e)

Fig. 7. Simulation of the BPSC strategy for Case 2: (a) phase voltages, (b) sequence voltages, (c) phase currents, (d) output power, (e) dc-link voltage. 


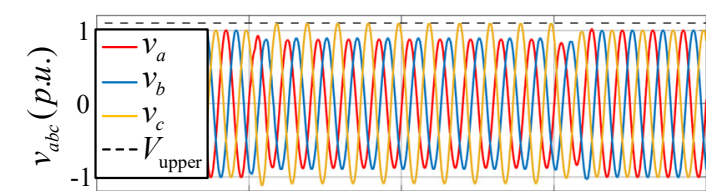

(a)
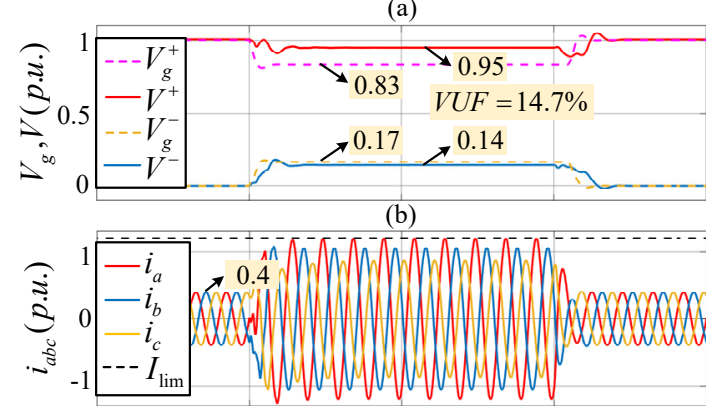

(c)

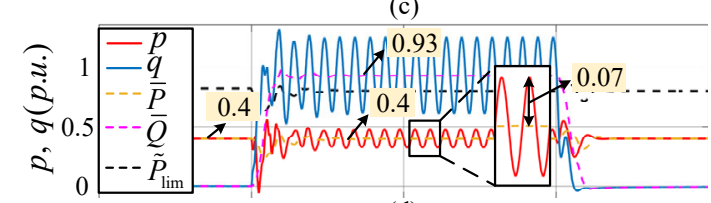

(d)

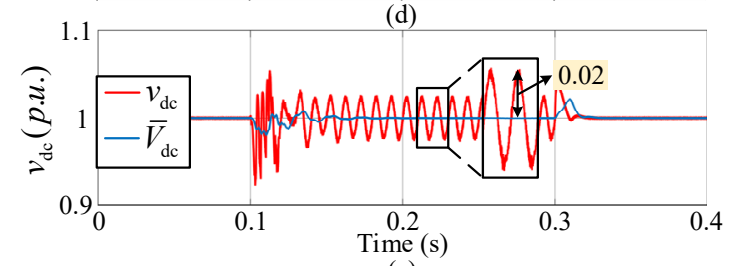

(e)

Fig. 8. Simulation of the proposed strategy for Case 3: (a) phase voltages, (b) sequence voltages, (c) phase currents, (d) output power (e) dc-link voltage.

maximum PV power due to the current limitation. Therefore, the non-MPPT of the boost converter is activated to reduce the generated PV power. As depicted in Fig. 6(d), the inverter output active power $\bar{P}$ decreased from 1p.u. to 0.76 p.u., and the overcurrent risk can be inherently avoided. Meanwhile, the active power oscillations are well controlled within the limits, which is 0.301 p.u.. As a result, the dc-link voltage oscillation is also limited to $7 \%$ of $V_{\mathrm{dc}}$, which is lower than $\tilde{V}_{\mathrm{dc} \_l i m}$.

Fig. 7(a) and (b) demonstrate the voltage support capability of the BPSC method is not fully exploited, where $V_{\max }<1.1$ p.u. and $V^{+}$is supported to 0.78 p.u. (lower than the proposed method, 0.85p.u.). As depicted in Fig. 7(c) and (d), both phase currents and power oscillations are within the constraints. Meanwhile, although BPSC strategy shows higher active power injection ability (0.91p.u.) than the proposed method (0.68p.u.), the delivered reactive power is obviously low, which is 0.24 p.u.

D. Case 3: Moderate Voltage Sag and Low Initial PV Power $\left(I_{p}^{+}, I_{q}^{+}\right.$, and $I_{q}^{-}$are Injected $)$

Fig. 8 presents the performance of IIDG during moderate voltage sag and low initial PV power scenario. As shown in Fig. $8(\mathrm{a})$, the voltage support capability is maximized, with $V_{\max }$ reaches to 1.1p.u.. Meanwhile, $V^{+}$is supported from 0.83p.u. to 0.95p.u. as shown in Fig. 8(b). As observed in Fig. 8(c), the inverter capacity is fully used $\left(I_{\max }=I_{\mathrm{lim}}\right)$ by the combined injection of $I_{q}^{-}$. And due to that, $V^{-}$is decreased from 0.17 p.u. to 0.15 p.u., which helps to reduce the voltage unbalanced factor (VUF). As revealed in Fig. 8(d), because the inverter can handle the maximum PV power, the boost converter is operating at the
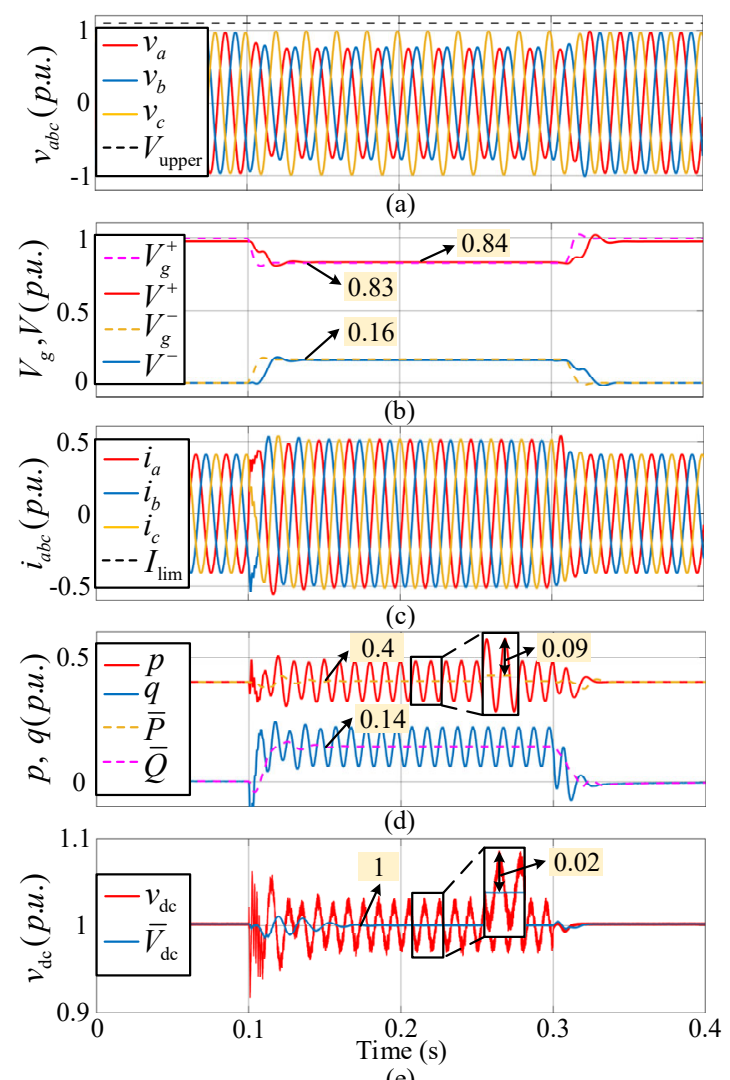

(e)

Fig. 9. Simulation of the BPSC strategy for Case 3: (a) phase voltages, (b) sequence voltages, (c) phase currents, (d) output power, (e) dc-link voltage.

MPPT mode. Therefore, the initial PV power delivery in this scenario is fulfilled with $\bar{P}$ remaining at 0.4 p.u.. Meanwhile, the delivered reactive power $\bar{Q}$ is relatively high, which is 0.93p.u.. Moreover, as depicted in Fig. 8(d) and (e), the oscillations of both active power and dc-link voltage are extremely low in this scenario.

As for the BPSC method, Fig. 9(a) and (b) indicate that the voltage support ability in this scenario is extremely low, with $V^{+}$supported by 0.01p.u.. As demonstrated in Fig. 9(c), although the phase currents remain balanced, the amplitude of the output current $\left(I_{\max }=0.51\right.$ p.u. $)$ is obviously lower than the limit $I_{\text {lim }}$, which means the inverter capacity is not fully used. Comparing Fig. 9(d) with Fig. 8(d), it is obvious that the delivered reactive power of BPSC method is lower than the proposed method. Moreover, due to the injection of $I_{q}^{-}$the proposed strategy shows lower active power oscillation (0.07p.u.) than the BPSC method (0.09p.u.).

\section{CONCLUSION}

System disturbances (e.g. voltage sags) can notably affect the safe and continuous operation of IIDGs. Many existing LVRT strategies show relatively weak voltage support capability and may be influenced by the DG capacity. Moreover, there are very few research activities that have considered multi-objective control of IIDG, which is necessary during the voltage sags.

Therefore, this paper has proposed a multi-objective control strategy for IIDG to improve its dynamic performance, while being capable of well-adapting to various operation scenarios. 
Three contributions have been made in this paper: 1) The proposed method can simultaneously realize and coordinate three critical control objectives, i.e., voltage support, current limitation, and oscillation suppression, during all voltage sag scenarios. 2) It only applies positive sequence voltage control, which can maximize the voltage support capability while lessaffected by the inverter capacity; 3) The proposed control strategy makes full use of the inverter capacity. In cases that the inverter has spare capacity after fully realizing such three objectives, the proposed method can use such spare capacity to achieve extra control objectives, such as actively improve system stability and voltage balance. Various simulation results comparing with the BPSC method are presented, which successfully validated the effectiveness of the new control method presented in this paper.

\section{REFERENCES}

1] J. Jia, G. Yang, and A. H. Nielsen, "A review on grid-connected converter control for short-circuit power provision under grid unbalanced faults," IEEE Trans. Power Del., vol. 33, no. 2, pp. 649-661, Apr. 2018.

[2] N. R. Merritt, C. Chakraborty, and P. Bajpai, "New voltage control strategies for VSC-based DG units in an unbalanced microgrid," IEEE Trans. Sustain. Energy, vol. 8, no. 3, pp. 1127-1139, Jul. 2017

[3] A. M. Stanisavljević and V. A. Katić, "Magnitude of voltage sags prediction based on the harmonic footprint for application in DG control system," IEEE Trans. Ind. Electron., vol. 66, no. 11, pp. 8902-8912, Nov. 2019.

[4] J. Fortmann et al., "Fault-ride-through requirements for wind power plants in the entso-e network code on requirements for generators," IET Renew. Power Gener., vol. 9, no. 1, pp. 18-24, Jan. 2015.

[5] Grid Code High and Extra High Voltage, E. ON Netz GmbH, Bayreuth, Germany, Apr. 2006. [Online] Available: http://www.pvupscale.org/.

[6] F. Wang, J. L. Duarte, and M. A. M. Hendrix, "Pliant active and reactive power control for grid-interactive converters under unbalanced voltage dips," IEEE Trans. Power Electron., vol. 26, no. 5, pp. 1511-1521, May 2011.

[7] M. M. Shabestary and Y. A. I. Mohamed, "An analytical method to obtain maximum allowable grid support by using grid-connected converters," IEEE Trans. Sustain. Energy, vol. 7, no. 4, pp. 1558-1571, Oct. 201

[8] Z. Shuai, C. Shen, X. Yin, X. Liu, and Z. J. Shen, "Fault analysis of inverter-interfaced distributed generators with different control schemes," IEEE Trans. Power Del., vol. 33, no. 3, pp. 1223-1235, Jun. 2018.

[9] W. Guo, L. Mu, and X. Zhang, "Fault models of inverter-interfaced distributed generators within a low-voltage microgrid," IEEE Trans. Power Del., vol. 32, no. 1, pp. 453-461, Feb. 2017.

[10] X. Guo, W. Liu, and Z. Lu, "Flexible power regulation and current-limited control of the grid-connected inverter under unbalanced grid voltage faults," IEEE Trans. Ind. Electron., vol. 64, no. 9, pp. 7425-7432, Sep. 2017.

[11] Y. Wang, P. Yang, X. Yin and Y. Ma. Evaluation of low-voltage ridethrough capability of a two-stage grid-connected three-level photovoltaic inverter[C]. International Conference on Electrical Machines and Systems. IEEE, 2014.

[12] C. Lee, C. Hsu, and P. Cheng, "A low-voltage ride-through technique for grid-connected converters of distributed energy resources," IEEE Trans on Ind. Appl., vol. 47, no. 4, pp. 1821-1832, Aug. 2011.

[13] M. M. Shabestary and Y. A. I. Mohamed, "Asymmetrical ride-through and grid support in converter-interfaced DG units under unbalanced conditions," IEEE Trans. Ind. Electron., vol. 66, no. 2, pp. 1130-1141, Feb. 2019.

[14] A. Camacho, M. Castilla, J. Miret, R. Guzmán, and A. Borrell, "Reactive power control for distributed generation power plants to comply with voltage limits during grid faults," IEEE Trans. Power Electron., vol. 29, no. 11, pp. 6224-6234, Nov. 2014.

[15] M. M. Shabestary and Y. A. I. Mohamed, "Advanced voltage support and active power flow control in grid-connected converters under unbalanced conditions," IEEE Trans. Power Electron., vol. 33, no. 2, pp. 1855-1864, Feb. 2018.

[16] J. Miret, A. Camacho, M. Castilla, J. L. G. de Vicuña, and J. de la Hoz, "Reactive current injection protocol for low-power rating distributed generation sources under voltage sags," IET Power Electron., vol. 8, no. 6, pp. 879-886, Jun. 2015

[17] A. Camacho, M. Castilla, J. Miret, J. L. G. de Vicuña, and R. Guzmán, "Positive and negative sequence control strategies to maximize the voltage support in resistive-inductive grids during grid faults," IEEE Trans. Power Electron., vol. 33, no. 6, pp. 5362-5373, Jun. 2018.

[18] A. Camacho, M. Castilla, J. Miret, P. Martí, and M. Velasco, "Maximizing positive sequence voltage support in inductive-resistive grids for distributed generation inverters during voltage sags," in Proc. 42th Annu. Conf. IEEE Ind. Electron. Soc., Oct. 2016, pp. 2343-2348.

[19] E. Afshari et al., "Control strategy for three-phase grid-connected PV inverters enabling current limitation under unbalanced faults," IEEE Trans. Ind. Electron., vol. 64, no. 11, pp. 8908-8918, Nov. 2017.

[20] H. D. Tafti, A. I. Maswood, G. Konstantinou, J. Pou, and P. Acuna, "Active/reactive power control of photovoltaic grid-tied inverters with peak current limitation and zero active power oscillation during unbalanced voltage sags," IET Power Electron., vol. 11, no. 6, pp. 10661073, 29 May 2018.

[21] X. Du, Y. Wu, S. Gu, H. Tai, P. Sun, and Y. Ji, "Power oscillation analysis and control of three-phase grid-connected voltage source converters under unbalanced grid faults," IET Power Electron., vol. 9, no. 11, pp. 21622173, Sep. 2016.

[22] H. Chen, C. Lee, P. Cheng, R. Teodorescu, and F. Blaabjerg, "A lowvoltage ride-through technique for grid-connected converters with reduced power transistors stress," IEEE Trans. Power Electron., vol. 31, no. 12 , pp. $8562-8571$, Dec. 2016

[23] M. A. Garnica López, J. L. Garcia de Vicuña, J. Miret, M. Castilla, and R. Guzmán, "Control strategy for grid-connected three-phase inverters during voltage sags to meet grid codes and to maximize power delivery capability," IEEE Trans. Power Electron, vol. 33, no. 11, pp. 9360-9374, Nov. 2018.

[24] N. Hoffmann and F. W. Fuchs, "Minimal invasive equivalent grid impedance estimation in inductive-resistive power-networks using extended Kalman-filter," IEEE Trans. Power Electron., vol. 29, no. 2, pp. 631-641, Feb. 2014.

[25] A. Vidal, et al., "A method for identification of the equivalent inductance and resistance in the plant model of current-controlled grid-tied converters," IEEE Trans. Power Electron., vol. 30, no. 12, pp. 7245-7261, Dec. 2015 .

[26] Metallized polypropylene film capacitors, Mouser Electronics., Mansfield, USA. [Online] Available: https://www.mouser.com Accessed on: Jun. 2018.

[27] P. Rodriguez, J. Pou, J. Bergas, J. I. Candela, R. P. Burgos, and D. Boroyevich, "Decoupled Double Synchronous Reference Frame PLL for Power Converters Control," IEEE Trans. Power Electron., vol. 22, no. 2 , pp. 584-592, Mar. 2007.

[28] V. L. Srinivas, B. Singh and S. Mishra, "Fault Ride-Through Strategy for Two-Stage Grid-Connected Photovoltaic System Enabling Load Compensation Capabilities," IEEE Trans. Ind. Electron., vol. 66, no. 11, pp. 8913-8924, Nov. 2019.

[29] P. Rodriguez, A. V. Timbus, R. Teodorescu, M. Liserre, and F. Blaabjerg "Flexible active power control of distributed power generation systems during grid faults," IEEE Trans. Ind. Electron., vol. 54, no. 5, pp. 25832592 , Oct. 2007

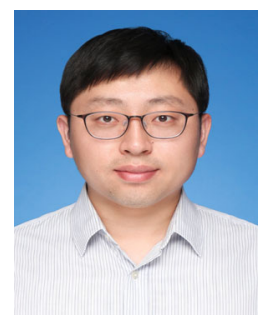

Liang Ji received his B.Eng. and Ph.D. degrees from University of Strathclyde, UK. He is presently an Associate Professor in the college of Electrical Engineering in Shanghai University of Electric Power, Shanghai. His research interests include the modeling and simulation for power system, power system protection and control. 


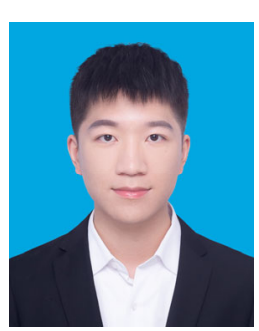

Jiabin Shi is working toward M. Eng. degree in the college of Electrical Engineering in Shanghai University of Electrical Power, Shanghai. His research interests include power electronics and control of power converters.

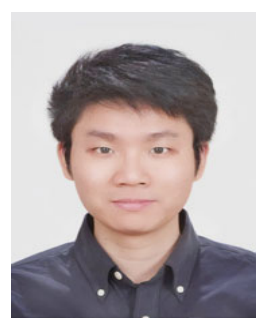

Qiteng Hong is currently a Chancellor's Fellow at the University of Strathclyde, Glasgow, U.K. His main research interest is on power system protection. He received his $\mathrm{Ph} . \mathrm{D}$. degree in Electronic and Electrical Engineering in 2015, from the University of Strathclyde. He is a Regular Member of the CIGRE Working Group B5.50, IEEE Working Group P2004.

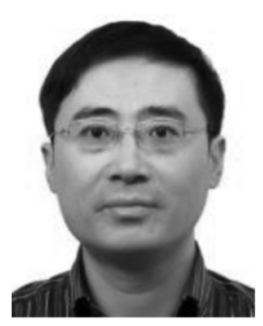

Yang Fu received the Ph.D. degree in electrical engineering from Shanghai University, Shanghai, China, in 2007. He is currently a Professor at Shanghai University of Electric Power, Shanghai, China. He is the corresponding author of this paper.

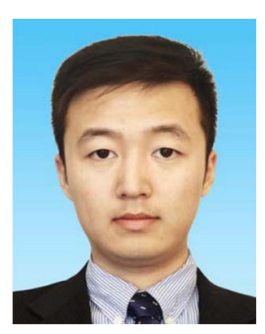

Xiao Chang is currently a senior engineer of Electric Power Research Institute of State Grid Jiangxi Electric Power Company, Nanchang, China. His research interests include new energy, power quality analysis, and energy storage application technology

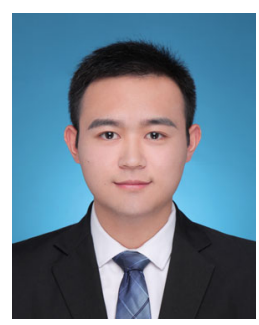

Che Cao is working toward M. Eng. degree in the college of Electrical Engineering in Shanghai University of Electrical Power, Shanghai. His research interest include microgrid control and protection

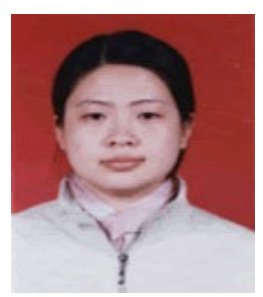

Yang Mi received the Ph.D. degree from Northeastern University, Shenyang, China. She is currently a Professor with Shanghai University of Electric Power, Shanghai. Her research interests include power system control and protection.

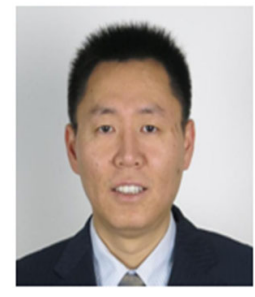

Zhenkun Li received the Ph.D. degrees from Hohai University, Nanjing, China. Currently, he is professor in Shanghai University of Electrical Power, China.

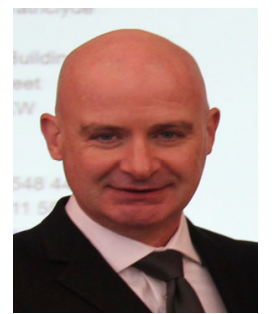

Campbell D. Booth received the B.Eng. and Ph.D. degrees in Electrical and Electronic Engineering from the University of Strathclyde, Glasgow, U.K., in 1991 and 1996, respectively. He is currently a Professor and Head of the Department for Electronic and Electrical Engineering, University of Strathclyde. His research interests include power system protection; plant condition monitoring, and applications of intelligent system techniques to power system monitoring, protection, and control. 